\title{
PROFESSORES DE EDUCAÇÃO FÍSICA E A PRODUÇÃO DOS SABERES: EM BUSCA DO FIO DA MEADA ${ }^{1}$
}

\author{
Ayra Lovisi Oliveira \\ Universidade Federal de Juiz de Fora, Juiz de Fora, Minas Gerais, Brasil \\ Ludmila Nunes Mourão \\ Universidade Federal de Juiz de Fora, Juiz de Fora, Minas Gerais, Brasil \\ Dinah Vasconcellos Terra \\ Universidade Federal Fluminense, Niterói, Rio de Janeiro, Brasil \\ Kalyla Maroun \\ Universidade Federal do Rio de Janeiro, Rio de Janeiro, Rio de Janeiro, Brasil
}

\begin{abstract}
Resumo
O objetivo foi compreender como são produzidos os saberes docentes de professores de Educação Física, considerando a influência de sua história de vida. A pesquisa seguiu a abordagem da etnografia educativa, com ênfase nos processos educativos de dois professores do ensino fundamental na rede pública da cidade de Juiz de Fora, Minas Gerais (MG). A reconstrução da biografia dos docentes evidenciou que a escolha de sua profissão está atrelada às histórias familiares e/ou sociais. A análise da prática profissional revelou que as intencionalidades dos professores estão ligadas ao desenvolvimento do prazer, da autonomia e da formação crítica dos alunos, e que os entraves da prática docente estão relacionados aos espaços, materiais, acúmulo de funções, indisciplina, turmas cheias e baixos salários.
\end{abstract}

Palavras-chave: Educação Física. Formação profissional. Docentes.

\section{Introdução}

O movimento pela profissionalização do ensino, iniciado na década de 1980, teve como uma de suas mais significativas contribuições o reconhecimento da existência de um conjunto de saberes específicos que caracterizam a profissão docente. Nóvoa (1995) e Tardif e Raymond (2000) são referências nesse campo de pesquisa, desenvolvendo estudos sobre saberes, formação e atuação docentes. No cenário nacional, podemos destacar autoras como Borges (1998) e Pimenta (1999), que foram pioneiras nas pesquisas nessa área. Esses pesquisadores vêm influenciando os modos pelos quais compreendemos a temática dos saberes docentes: uma área que se destaca no contexto das pesquisas educacionais a partir da década de 1990, especialmente em Educação Física.

Por meio das pesquisas desenvolvidas pelos autores acima citados, compreendemos que o professor, ao desenvolver seu trabalho, mobiliza uma pluralidade de saberes voltados tanto ao seu processo de formação profissional, quanto às suas experiências de vida e do cotidiano docente. Entender a formação docente de acordo com essa epistemologia formativa

\footnotetext{
${ }^{1} \mathrm{O}$ presente trabalho contou com o apoio financeiro da CAPES para a sua realização.
} 
significa compreender os professores como indivíduos cujas vidas pessoais e profissionais se modelam mutuamente.

Nesse sentido, a epistemologia formativa remete ao processo de construção da docência e dos saberes que a envolvem ao longo da história de vida do professor. As trajetórias que os profissionais percorrem, incluindo o período que compreende a infância e a adolescência, o momento de formação acadêmica e a etapa da prática docente, são fortes influenciadores de suas ações durante o exercício da profissão. Os professores são profissionais que ficaram imersos em seu ambiente de trabalho durante grande parte de suas vidas, antes mesmo de exercerem a profissão. Desse modo, tal imersão traz como consequência uma bagagem de conhecimentos prévios, crenças, representações e certezas sobre a prática docente. Esse legado da socialização escolar permanece forte e estável através do tempo (TARDIF, 2011).

Outras relações sociais - por exemplo, os amigos, a religião, experiências culturais vividas no universo das artes (teatro, dança), ou mesmo atividades de cunho coletivo vividas no tempo de lazer ou no contato com o esporte - compõem o ser professor e o seu saber-fazer pedagógico (GARIGLIO, 2004). Assim, na construção dos saberes docentes, os processos de formação da pessoa e do professor são fundamentais para a compreensão da prática pedagógica, uma vez que nos tornamos professores por inteiro. Temos, assim, o rompimento da ideia de que a formação se restringe a quatro ou cinco anos da formação inicial, para a ideia do continuum, que percorre a vida profissional e pessoal do docente.

A produção dos saberes docentes é dotada de intencionalidades que variam segundo a formação, história de vida e ideologias a que os professores foram submetidos. Para entender como esses saberes se constituem, é necessário que os docentes reflitam sobre suas ações e objetivos no ato de ensinar, na medida em que só constituem "saberes" os pensamentos, as ideias, as ações, os discursos e os argumentos que obedecem a certas exigências de racionalidade. "Eu falo ou ajo racionalmente, quando sou capaz de justificar, por meio de razões, de declarações, de procedimentos, diante de outro ator que me questiona sobre a pertinência e o valor deles" (TARDIF, 2011, p. 199).

A partir desse olhar, o objetivo do presente estudo é compreender como são produzidos os saberes docentes de professores de Educação Física, considerando: a influência de suas histórias de vida; a formação inicial a que foram submetidos; suas respectivas marcas de socialização primária e de profissionalização; e, finalmente, a reflexão sobre os saberes por eles produzidos em suas respectivas práticas pedagógicas.

\section{Percurso metodológico}

Esta pesquisa pautou-se em uma abordagem teórico-metodológica qualitativa, que dá voz ao professor, analisando sua trajetória profissional e história de vida.

De acordo com Nóvoa (1995), essa abordagem se encontra em oposição aos estudos que reduziam a profissão docente a um conjunto de competências e técnicas que terminavam por produzir uma crise de identidade dos professores, na medida em que separavam o eu profissional e o eu pessoal. Contrariamente, essa nova perspectiva de investigação coloca o professor como foco central em estudos e debates, enfatizando o quanto o "modo de vida" pessoal acaba por interferir no profissional. Esse movimento surgiu "num amálgama de vontade de produzir outro tipo de conhecimento, mais próximo das realidades educativas e do quotidiano dos professores" (NÓVOA, 1995, p. 19).

Para a tarefa, optamos pela etnografia da prática escolar que, segundo André (1995), é uma adaptação da etnografia à educação, em que o foco principal de investigação são as ações e relações que configuram o cotidiano das escolas. 
Elegemos como campo empírico duas escolas públicas municipais da cidade de Juiz de Fora-MG, que oferecem o ensino fundamental do $6^{\circ}$ ao $9^{\circ}$ ano. Durante cinco meses, observamos dois docentes de Educação Física em suas práticas pedagógicas, sendo 21 aulas de cada um deles. Utilizamos o diário de campo para registro dos dados observados e realizamos uma entrevista em profundidade com os professores, levando em conta os diferentes aspectos de sua história individual e profissional.

Optamos por denominar os docentes analisados de Zeus e Hera para preservar suas identidades. Zeus se formou no ano de 2008 e atua como docente na rede municipal de ensino há três anos; Hera obteve sua formação no ano de 1981, e possui 25 anos de experiência docente na rede municipal.

Os procedimentos éticos foram observados para a realização da pesquisa, e aprovados pelo Comitê de Ética em Pesquisa da UFJF, sob o parecer no 336/2011.

A análise dos dados empíricos resultou em cinco categorias analíticas: i) profissão professor: escolher ou ser escolhido - busca analisar como se deu a escolha pela profissão; ii) marcas, ações e reflexões da socialização primária - procura destacar aspectos relevantes do período escolar dos docentes presentes na produção dos seus saberes; iii) marcas, ações e reflexões da profissionalização - objetiva desvelar a influência da formação profissional na prática docente; iv) ações e reflexões da atuação profissional: o início da carreira - busca demonstrar as dificuldades da carreira docente e a influência do ambiente de trabalho na produção dos seus saberes; e v) reflexões sobre a docência - traz uma ponderação dos docentes sobre os saberes produzidos por eles.

\section{Profissão professor: escolher ou ser escolhido}

A escolha da profissão é um momento crucial na vida do ser humano e, geralmente, é cercada de dúvidas e incertezas, pois a partir dela será traçado um caminho a ser seguido. Podemos dizer que a decisão por qual profissão seguir é o resultado do encontro de um conjunto de fatores culturais e sociais que, aliados às condições subjetivas, constituem a própria vida em construção (SANTOS; BRACHT; ALMEIDA, 2009).

Zeus descreve esse emaranhado de experiências na escolha da sua profissão:

Com 12 anos comecei a dar aula particular de português e matemática e gostei... E na época estava tendo intercolegial... minha escola só levava a equipe de futebol masculino e de handebol feminino... eu não era bom de futebol... mas sabia correr, ... então cheguei pra professora e falei... tem atletismo no intercolegial? Ela falou... tem, mas tem que montar equipe e eu não tenho tempo... falei... eu monto. Aí fiz um movimento na escola... montei a equipe... peguei um livro de atletismo que tinha na escola, li, treinei os meninos, fomos para o centro olímpico da UFJF... e quando passei lá no centro olímpico, passei pela faculdade, ... falei assim, legal, vou fazer educação física, o espaço tem muitas coisas diferentes...

Já a escolha de Hera pela profissão está mais atrelada à sua história de vida familiar e, ao que é mais comum de se encontrar na escolha pela Educação Física, às experiências corporais: "Na época, vários anos atrás, não tinha muita opção de curso..., mas sempre gostei de ginástica, dança, trabalhar o corpo, e na família já tem outros professores... acho que é um pouco genético, minha mãe, minhas irmãs, minhas tias...”.

Ao investigar em que as pessoas se orientam no momento da escolha da profissão, o estudo de Lassange (1997) aponta para os falsos cognatos, ou seja, falsas aptidões. Dois dos falsos cognatos se relacionam com as narrativas dos professores Zeus e Hera, são eles: habilidades específicas - no caso em que o jovem associa, por exemplo, que ter habilidades em algum esporte está ligado à Educação Física; e ao contato direto com a atividade 
relacionada - tendo pouco contato com diferentes áreas ocupacionais, é comum que o jovem se decida por uma que esteja diretamente relacionado.

Zeus pautou sua escolha nas condições objetivas de vida e no interesse, que, somados a um comportamento audacioso e autônomo, o levaram a articular experiências em sua história de vida, culminando na escolha da profissão. Quanto à Hera, os exemplos familiares foram capazes de subjetivar experiências de vida com práticas corporais de sucesso, as quais potencializaram o seu gosto e a influenciaram na escolha da profissão.

As narrativas de Zeus e Hera corroboram com as pesquisas sobre o tema, as quais sinalizam que as experiências sociais, culturais e corporais, cujas origens remontam suas histórias de vida, são determinantes na escolha da profissão e posterior envolvimento nos cursos de formação inicial (SANTOS; BRACHT; ALMEIDA, 2009; AMORIM FILHO; RAMOS, 2010).

\section{Marcas, ações e reflexões da socialização primária}

Partindo da premissa de que as experiências que antecedem a formação profissional tornam-se relevantes para entendermos como são construídos os saberes docentes, na medida em que suas decisões e ações também se baseiam nos hábitos e crenças que são construídos ao longo da sua história de vida, concordamos com Tardif e Raymond (2000, p. 235), quando afirmam que:

[...] um professor "não pensa somente com a cabeça", mas "com a vida", com o que foi, com o que viveu, com o que acumulou em termos de experiência de vida, em termos de lastros de certezas. Em suma, ele pensa a partir da sua história de vida, não somente intelectual no sentido rigoroso do termo, mas também emocional, afetiva, pessoal e interpessoal [...].

Ao indagar sobre suas experiências na fase da infância e adolescência com as aulas de Educação Física, Hera e Zeus, respectivamente, revelaram: "Não eram muito diversificadas não... o professor mandava correr... depois fazer caminhada em volta da quadra... jogar vôlei e queimada...".

\footnotetext{
Aconteciam em duas aulas por semana... a escola tinha um pátio de terra e uma quadra.... Um dia a quadra era para os meninos e no outro para as meninas. Eu não podia fazer aula no pátio de terra porque tenho asma. No dia da quadra dos meninos eles não me deixavam jogar porque eu era ruim de bola. Não é que eu era ruim de bola, era peladeiro de rua, jogava descalço, tirava meu tênis jogava bem, botava o tênis era horrível... e a professora da época... não tinha organização, era sempre a mesma coisa futebol e queimada... e pingue-pongue, para quem não fazia nenhum dos dois.
}

A partir dessas falas, percebemos que os professores foram influenciados de diferentes formas no passado, o que implicou interpretações diferentes. Zeus, de acordo com sua experiência de aluno, e posteriormente de professor de Educação Física, revela: “... minha professora na época... não tinha organização...". Suas memórias mostram que as diferentes formas pelas quais o passado nos influencia articulam-se e se identificam com as novas experiências, legitimando a produção de saberes continuamente. Sendo assim, o fato de Zeus criticar a desorganização de sua professora o influenciou na sua valorização por uma educação sistematizada, planejada e com objetivos definidos, ou seja, no seu desenvolvimento organizacional para o trabalho, como verificaremos adiante neste estudo.

Por outro lado, Hera relata não ter muitas lembranças, mas isso não significa que suas experiências não influenciaram sua prática pedagógica. Hera tem 25 anos de formada. A vida 
de estudante ficou mais distante, entretanto, houve momentos em que observamos algumas semelhanças em suas aulas com as experiências relatadas, por exemplo, ao solicitar que os alunos corressem em torno da quadra.

Outra questão abordada com os docentes foi sobre suas experiências corporais anteriores ao ingresso no ensino superior. Zeus revelou que, apesar da vontade de aprender futebol em uma escolinha, sua condição social não permitiu. Assim, suas experiências corporais se deram na infância com as brincadeiras de rua. Hera se recorda de que sempre gostou de "trabalhar o corpo", como diz: "já havia feito ginástica e na adolescência fiz ballet".

Ao refletirmos sobre as ações dos docentes e os saberes produzidos por eles, relacionados às suas histórias de vida, as aulas observadas em nossa pesquisa de campo evidenciaram, no caso de Zeus, que o seu planejamento se baseia em uma concepção pedagógica crítica da Educação Física. Há marcas bastante significativas, como a preocupação em não provocar a "exclusão" dos alunos das atividades, além de não haver uma supervalorização da indumentária própria para as aulas de Educação Física, a exemplo de um aluno que realizou uma aula descalço.

As marcas observadas em Hera estão relacionadas a uma preocupação com o ensino da técnica e com o desenvolvimento da saúde de seus alunos: “... educação física serve pra melhorar a saúde, então a gente está sempre falando sobre isso...". Nesse sentido, observamos em suas aulas alongamentos, atividades que envolvem corridas, pular corda, estafetas, dentre outras, evidenciando o resgate das brincadeiras que vivenciou na infância. Suas aulas se baseiam: “... nas coisas que aprendia... acho que é tudo um processo que vai desde as brincadeiras que eu fazia quando criança... que achava interessante, então passava isso para os alunos...”.

Foi possível verificar nas narrativas dos docentes que as experiências vividas na fase de socialização pré-profissional deixaram marcas e influenciaram na produção de seus saberes. A esse processo de socialização que antecede a entrada no ensino superior denominase socialização primária ou socialização pré-profissional, diferentemente da socialização secundária, que remete à formação profissional propriamente dita (TARDIF, 2011; PIMENTA, 2002). Em suma, a socialização pré-profissional caracteriza-se por conhecimentos provenientes da formação escolar, tendo como fontes sociais de aquisição a escola primária e secundária, os estudos pós-secundários não especializados, além da socialização familiar e o contato com diferentes formas de socialização (religião, lazer, esportes). Já a socialização profissional tem como referência os saberes provenientes da formação profissional para o magistério, adquiridos dentro das instituições de formação de professores por meio das disciplinas oferecidas e dos estágios supervisionados.

\section{Marcas, ações e reflexões da profissionalização}

O período acadêmico corresponde ao início da formação profissional sistematizada. É a fase em que o futuro professor adquire grande parte dos conhecimentos específicos. Entretanto, há uma crítica recorrente na área, segundo a qual a formação acadêmica está muito distante da prática profissional, o que caracteriza a dicotomia entre teoria e prática.

Tal problema também é apontado por Darido (2003, p. 26) ao questionar os docentes de Educação Física sobre a formação profissional: "as disciplinas devem ser mais teóricopráticas; tem que ter mais experiência". Relatos como "a pessoa chega lá fora e é aquele choque quando vai dar aula" demonstram que o abismo entre a teoria e a prática na Educação Física é um desafio central a ser superado no chamado currículo científico, em que a formação está focada no aprender a ensinar, a partir de subsídios tanto das ciências biológicas, como das ciências humanas e sociais. Os depoimentos transcritos acima reforçam a 
necessidade de se pensar a formação em Educação Física, especialmente no que se refere à integração ou não dicotomização entre teoria e prática.

Ao indagarmos aos docentes como sua formação profissional contribuiu para a sua prática profissional, Zeus e Hera destacaram, respectivamente:

Meu curso era de licenciatura plena, então teoricamente as disciplinas, vamos dizer assim, da faculdade de educação física: iniciação ao atletismo, basquete, futebol... a dimensão técnica dos fundamentos, da prática dos esportes, vou dividir assim... eu aproveito pra trabalhar determinados aspectos desses esportes... O trato pedagógico, a gente vai pra parte das disciplinas da faculdade de educação... elas me ampararam teoricamente pro conteúdo, mas esse link pegar o conteúdo específico... a luta, o esporte, a dança enfim, pegar o conhecimento, a teoria, a abordagem, o conhecimento técnico, e fazer essa mistura isso ficou faltando... faltou um pouco de chão de escola...

... ficou muita coisa vaga, na época eram só três anos... então saíamos da faculdade despreparados... acho que é pouco tempo de formação acadêmica... ficou muito a desejar... muita matéria não foi bem dada... de algumas aulas depois eu tive que aprender por minha conta, na prática era bem diferente da teoria, então corri atrás.

Os docentes analisam sua formação inicial, falam de algumas falhas, como a ausência de relação entre as aprendizagens teóricas e as experiências práticas, evidenciadas em falas como "falta um pouco de chão da escola" e "a prática era bem diferente da teoria". Os relatos de Zeus e Hera foram encontrados também no estudo de Borges (1998), cujos docentes destacam como positivas, em sua formação, apenas as disciplinas que, de alguma forma, aproximam-se dos saberes práticos, do saber-fazer. Ainda, segundo o estudo, ao concluir a formação inicial, os docentes sentem uma "sensação de vazio", de "despreparo para intervenção profissional". Os professores analisados por Gariglio (2004) também criticam a instituição formadora, contudo, o autor esclarece que não se trata de negar o papel da teoria, mas de apontar a impropriedade com que esta foi oferecida no curso.

Nossos professores são categóricos ao afirmar que a formação está muito distante da realidade vivida nas escolas, corroborando com vários estudos (BORGES, 1998; GARIGLIO, 2004; SANTOS; BRACHT; ALMEIDA, 2009; AMORIM FILHO; RAMOS, 2010). Para complementar essa informação, perguntamos aos professores quais conteúdos da formação inicial eram mais utilizados em seus planejamentos e em suas aulas. Zeus e Hera responderam, respectivamente: "esporte ponto... quadrado mágico [futebol, vôlei, basquete, handebol]", e "ginástica escolar". Podemos perceber que as contribuições creditadas pelos docentes à sua formação inicial são relacionadas a conteúdos de ordem prática.

Ao abordar a necessidade de uma formação inicial que capacite os professores de Educação Física para trabalharem na escola, obtivemos o seguinte depoimento de Hera:

... tem que ter mais parte prática... mais estágio supervisionado e trabalhar mais nas escolas... é mais interessante... acho que falta muito, mais teoria, a parte prática fica muito falha... depois na escola temos que complementar com cursos..., mas a faculdade tem que tratar dessa parte prática...

O posicionamento de Hera vem corroborar com as ideias de Tardif (2011) quando este diz que o saber dos professores é um saber do trabalho, e não um saber sobre o trabalho, devendo ser compreendido em íntima relação com o trabalho deles na escola e na sala de aula. É preciso não exatamente esvaziar a lógica disciplinar dos programas de formação para o ensino, mas fundamentá-la na análise das práticas, das tarefas e dos conhecimentos dos professores de profissão; ela deve proceder por meio de um enfoque reflexivo, levando em conta os condicionantes reais do trabalho docente. 


\section{Ações e reflexões da atuação profissional: o início da carreira}

Ao iniciarem a carreira, os professores começam a construir os seus saberes da experiência. Pode-se chamar de "saberes experiências" o conjunto de saberes atualizados, adquiridos e necessários no âmbito da prática da profissão docente, os quais se constituem por meio de relações e interações que os professores estabelecem e desenvolvem com os demais atores do campo de sua prática, as diversas obrigações e normas às quais seu trabalho deve submeter-se, e a instituição como meio organizado e composto de funções diversificadas (TARDIF, 2011).

Nesse contexto, o início da carreira docente pode apresentar situações problemáticas, uma vez que, em função da inexperiência, o professor pode ter dificuldade em lidar com alguns desafios. Ao indagarmos os docentes pesquisados sobre as principais dificuldades do início da carreira, Hera relata que: “... foi com a disciplina dos alunos, ao querer passar os conteúdos eles tinham outras opções, jogar bola, acham que... educação física é mais futebol, queimada, então às vezes, quando queria mudar, até hoje tem essa resistência...".

Zeus nos diz que quando chegou à escola para trabalhar não teve oportunidade de escolher as turmas para as quais iria ministrar aulas, pois os professores mais experientes já haviam escolhido as de sua preferência, e o que "sobrou" ficou com ele. Além disso, ele não contou com o auxílio da coordenação da escola no planejamento de suas atividades, nem mesmo dos colegas. Percebemos, no nosso caso, que esse isolamento partiu da própria instituição, que não acolhe e não dá suporte aos professores no início da carreira.

Em relação aos colegas de profissão, Hera relata que geralmente eles se reúnem quando vai haver algum evento envolvendo todas as turmas, como: interclasse, festa junina, entre outros; e que os espaços dados à Educação Física nas reuniões pedagógicas destinam-se à discussão sobre os eventos que são atribuídos à disciplina. Zeus relata que, ao iniciar suas atividades na escola, sentia certa insegurança em planejar sozinho, uma vez que esse tipo de atividade era realizado em duplas durante sua experiência no estágio supervisionado do curso de graduação. Por não ter conseguido se articular com os colegas para planejar na escola, ele busca o apoio de amigos professores da rede municipal, que trabalham em outras escolas, para planejarem juntos. Zeus considera enriquecedora essa experiência, a ponto de já estarem pensando em lançar um livro e um blog com os planos de aulas do grupo.

Outras pesquisas revelam que, na busca de visibilizar a Educação Física no cotidiano da escola, os docentes - assim como Hera - acabam assumindo inúmeras funções que não fazem parte dos objetivos da disciplina (festas juninas, competições, entre outros) na busca por reconhecimento. Tal fato pode estar relacionado à hierarquia dos saberes escolares, que concebe a Educação Física como disciplina de menor prestígio, devido à função de formar os alunos na perspectiva do saber-ser e do saber-fazer (COSTA; MENDONÇA; TERRA, 2010; GARIGLIO, 2004).

Por meio do exemplo de Zeus, observamos que o trabalho em conjunto, além de diminuir a insegurança do professor iniciante na carreira em relação ao planejamento, pode desencadear uma política interinstitucional de desenvolvimento da Educação Física. Tal alternativa contribui, dentre outros aspectos, para valorizar o planejamento dentro do sistema escolar, além de enriquecer e promover a formação ampliada dos educadores participantes. De acordo com Zeus, "é muito mais produtivo e prazeroso o trabalho em grupo".

\section{Reflexões sobre a docência}


Sabemos que a prática docente é repleta de intencionalidades: quando selecionamos os conteúdos a serem trabalhados, a forma como iremos trabalhá-los, todas essas ações têm um objetivo, uma intenção. Ao refletirem sobre sua docência, os professores verbalizam que:

Você nota nos meninos uma visão diferente das coisas, hoje tenho segurança em deixar eles organizarem o futebol... têm a capacidade de me pedir o material, por exemplo, de badminton... Você vê os meninos aqui na faculdade jogando Rugby e futebol americano... quer dizer esse saber, essa teoria, eles estão pegando para a prática, para a vida social deles... Autonomia, e estão tendo senso crítico, como na questão das lutas, muitos aqui fazem Muay Thai, Jiu Jitsu e têm a noção de que não é para lutar na rua, não é violência... (Zeus)

Eles gostam, se sentem motivados, gostam de participar da educação física... às vezes... quando eu quero mudar, fazer uma aula diferente, tem um pouco de resistência, mas depois eles vêem que é importante e valorizam. É um momento que eles têm... de ter um prazer... momento de integração, de troca... isso tudo pra eles é um crescimento, valorizam, gostam da aula... às vezes encontro com ex-aluno no cinema...oh professora, sua aula era legal... (Hera)

Como mostram os docentes, suas intencionalidades são diferentes. Hera está mais preocupada com o prazer que os alunos sentem nas aulas, baseando-se na vivência em atividades diversificadas e em desenvolver a interação dos alunos. Zeus está preocupado em desenvolver a autonomia e o senso crítico dos alunos em seu planejamento e ações, focando na reflexão com os alunos sobre a história das práticas corporais, suas contextualizações, além das vivências nas atividades.

Por fim, solicitamos aos professores, após refletirem sobre sua formação, história de vida e intencionalidades, que apontassem as maiores dificuldades da prática pedagógica e discorressem sobre o que acreditam ser importante para se tornar um bom professor de Educação Física. Zeus relata que:

Os maiores entraves que a gente tem são aqueles que vêm acima da gente, turma com 35 alunos, 18 aulas por semana... aluno repetente que tá fora da faixa etária... ganhando o que ganhamos com curso superior... você tem que pegar dois cargos... Hoje um professor para se tornar bom professor de escola... tem que ter uma paciência de Jó, para aguentar tudo que falei e aguentar uma penca de adolescentes que não querem nada da vida... tem que se preparar psicologicamente para aguentar esse tipo de coisa, e aguentar as condições de trabalho, e as limitações que o curso traz...

Hera reafirmou vários aspectos já apresentados por Zeus, complementando sobre o que acredita ser necessário para seguir a carreira docente:

Tem que ter, primeira coisa, paciência, tolerância, ser bem flexível... saber escutar o aluno, respeitar a individualidade do aluno... ter muito jogo de cintura ... e, principalmente, respeito por eles ... conhecimento das aulas, dos esportes ... E gostar do que faz, ter disposição, achar que sempre pode melhorar, nunca ficar parado, ter sempre ideias novas, buscar coisas novas...

Podemos perceber que, diante dos entraves relacionados ao trabalho na escola, os professores destacam a necessidade de construção de saberes docentes que vão além do conhecimento do conteúdo, ou seja, eles sinalizam para a importância de serem constituídos saberes relacionados, por exemplo, à interação com os alunos, tais como paciência, respeito, jogo de cintura, tolerância.

Borges (1998) já apontava em sua pesquisa que o saber dos professores é determinante e determinado, ou seja, é um saber situado, produzido no contexto de trabalho. Acreditamos, 
assim, que as condições de trabalho dos docentes também são determinantes na produção de seus saberes.

\title{
Considerações finais
}

Em busca do fio da meada, optamos por observar os docentes no intuito de levantarmos fatos que nos ajudassem a compreender como os professores constituem os saberes que utilizam em sua prática pedagógica. No desenrolar desse novelo, a reconstituição das histórias de vida e as reflexões dos professores se mostraram fundamentais, pois as marcas deixadas pelas diferentes fases de sua vida os ajudaram a constituir suas carreiras e seus saberes.

Como já mencionado, não é possível distinguir o pessoal do profissional. $\mathrm{O}$ fio da meada é único, assim como seus nós e sua história. Ao reconstruirmos as biografias dos docentes, descobrimos que a escolha de sua profissão está atrelada às suas histórias familiares e/ou sociais. Marcas da socialização primária também foram percebidas nas práticas pedagógicas, tais como a experiência como alunos de Educação Física na escola e as experiências corporais, seja de uma infância rica em brincadeiras, ou da prática da atividade física sistematizada.

Ao analisar a prática pedagógica dos professores, observamos que Hera tem como objetivo, em suas aulas, o desenvolvimento do prazer dos alunos, e Zeus, a autonomia e a formação crítica dos mesmos. Os docentes explicitaram que os entraves para o desenvolvimento da prática docente estão relacionados aos espaços, aos materiais, ao acúmulo de funções em busca de reconhecimento no espaço escolar, a indisciplina dos alunos, as turmas cheias e os alunos repetentes - aos quais se somam os baixos salários, que os levam a acumularem cargos para complementarem a renda.

Conclui-se que há necessidade de ampliar o apoio pedagógico da escola no início da carreira docente. $\mathrm{O}$ descaso da escola em acolher os docentes recém-chegados ficou evidente, e a nosso ver, são esses os que necessitam de apoio. Nesta pesquisa isso se deveu ao fato de os entrevistados deixarem a graduação se sentindo "despreparados" e "inseguros" para realizar sozinhos sua atividade docente. O trabalho em conjunto foi uma estratégia utilizada que se mostrou motivadora e produtiva, e proporcionou acolhimento aos docentes.

Diante da solicitação feita aos professores integrantes da pesquisa de uma reflexão sobre o que acreditam ser necessário para se trabalhar na escola, eles elencaram qualidades que não se relacionam aos saberes dos conteúdos da disciplina, mas sim, aos entraves da prática docente - como paciência, tolerância, respeito, jogo de cintura, dentre outras.

O estudo realizado evidenciou, portanto, que todas as marcas encontradas ao longo do fio é que determinam a constituição dos docentes e de seus saberes, os quais estão ligados a diversos fatores e momentos da vida (do) docente. Assim, podemos dizer que os saberes docentes se mostram como determinantes na construção da identidade desses professores.

\section{PHYSICAL EDUCATION TEACHERS AND THE PRODUCTION OF KNOWLEDGE: IN SEARCH OF THE TRAIN OF THOUGHT}

\begin{abstract}
This study aimed at understanding how the teaching knowledge of Physical Education teachers is produced, considering the influence of the story of life. The study followed the approach of educational ethnography, with emphasis on the educational process of two elementary public school teachers in the city of Juiz de Fora, Minas Gerais (MG). The reconstruction of the teachers' biography showed that the choice for their profession is linked
\end{abstract}


to family and/or social stories. The analysis of professional practice revealed that the intentions of teachers are linked to the development of pleasure, autonomy and critical training of students, and that the obstacles of teaching practice are related to space, materials, accumulation of functions, indiscipline, full classes and low wages.

Keywords: Physical Education. Professional Qualification. Teachers.

\section{PROFESORES DE EDUCACIÓN FÍSICA Y LA PRODUCCIÓN DE SABERES: EN BUSCA DE UNA LÍNEA DE PENSAMIENTO}

\section{Resumen}

El objetivo fue entender cómo se producen los saberes de los profesores de educación física, considerando la influencia de su historia de vida. La investigación siguió los preceptos teóricos de la etnografía educativa, destacando los procesos educativos de dos profesores de la enseñanza primaria de la red pública de la ciudad de Juiz de Fora (MG). La reconstrucción de la biografía de los docentes demostró que la elección de su profesión está vinculada a sus historias familiares y / o historias sociales. El análisis de la práctica profesional reveló que las intencionalidades de los profesores se relacionan con el desarrollo del placer, la autonomía y la formación crítica de los estudiantes y las barreras de la práctica docente se relacionan con el espacio, los materiales, la acumulación de funciones, la indisciplina, las aulas superpobladas y los salarios bajos.

Palabras clave: Educación Física. Formación Profesional. Profesores.

\section{Referências}

ANDRÉ, M. E. D. A. Etnografia da Prática Escolar. Campinas, SP: Papirus, 1995.

AMORIM FILHO, M. L.; RAMOS, G. N. S. Trajetória de vida e construção dos saberes de professores de Educação Física. Revista Brasileira de Educação Física e Esporte, São Paulo, v. 24, n. 2, p. 23-38, abr./jun. 2010.

BORGES, C. M. F. O professor de educação física e a construção do saber. Campinas, SP: Papirus, 1998.

COSTA, M. C. S.; MENDONÇA, M. S. S.; TERRA, D. V. A prática pedagógica de uma professora de Educação Física: mergulhando no universo de uma escola pública do Estado do Amapá. Revista Brasileira de Ciências do Esporte, Campinas, v. 31, n. 2, p. 215- 230, jan. 2010.

DARIDO, S. Educação Física na escola: questões e reflexões. Rio de Janeiro, RJ: Editora Guanabara, 2003.

GARIGLIO, J. A. A cultura docente de professores de Educação Física de uma escola profissionalizante: saberes e práticas profissionais em contexto de ações situadas. 2004. 291 f. Tese (Pós-Graduação em Educação) - PUC-Rio, Rio de Janeiro-RJ, 2004.

LASSANGE, M. C. P. Orientação profissional e a globalização da economia. Revista ABOP, Porto Alegre, 1997. 
NÓVOA, A. Os professores e suas histórias de vida. In: NÓVOA, A. Vida de professores. Porto: Porto, 1995.

PIMENTA, S. G. Formação de professores: identidade e saberes da docência In: PIMENTA, Selma Garrida (Org.). Saberes pedagógicos e atividade docente. São Paulo: Cortez Editora, 1999, p. 15-34.

PIMENTA, S. G. Saberes pedagógicos e atividade docente. São Paulo, SP: Cortez, 2002.

SANTOS, N. Z.; BRACHT, V.; ALMEIDA, F. Q. Vida de professores de educação física: o pessoal e o profissional no exercício da docência. Revista Movimento, Porto Alegre, v. 15, n. 2, p. 141-165, abr./jun. 2009.

TARDIF, M.; RAYMOND, D. Saberes, tempo de trabalho no magistério. Revista Educação \& Sociedade, Campinas, n. 73, p. 209-244, 2000.

TARDIF, M. Saberes docentes e formação profissional. 12. ed. Petrópolis, RJ: Vozes, 2011.

Recebido em: 15/10/2015

Revisado em: 31/03/2016

Aprovado em: 03/05/2016

Endereço para correspondência:

mouraoln@gmail.com

Ludmila Nunes Mourão

Universidade Federal de Juiz de Fora

Rua José Lourenço Kelmer, S/n

Martelos, Juiz de Fora - MG, 36036-330 